\title{
Covid-19, o novo coronavírus: um alerta emergencial para as principais estratégias de prevenção da saúde pública
}

Introdução: O novo Coronavírus um tipo de vírus, já identificado, como um agente etiológico desencadeador de um alarmante surto de uma doença respiratória ocasionando uma pneumonia de origem desconhecida, que desencadeou a disseminação primária na cidade de Wuhan, localizada na China. Objetivo: Conhecer as possíveis formas de orientação para os órgãos Sistema Nacional de Vigilância em Saúde em parceria com os serviços da Atenção Primária à Saúde, para atuarem na identificação de casos, realização de notificações e no referenciamento dos casos suspeitos pela infecção decorrente do Coronavírus. Método: Para o desenvolvimento deste estudo foi realizada uma revisão de literatura, caracterizando-se na análise das informações disponíveis em um dado momento e sobre uma problemática específica. Assim, o presente estudo é de natureza descritiva, com abordagem qualitativa conforme. A busca pelos artigos se deu nas bases de dados Scientific Electronic Library Online (SciELO), Biblioteca Virtual em Saúde (BVS) e Google Acadêmico. Para os critérios de inclusão utilizados, foram selecionados artigos deu nas bases de dados Scientific Electronic Library Online (SciELO), Biblioteca Virtual em Saúde (BVS) e Google Acadêmico. Para os critérios de inclusão utilizados, foram selecionados artigos
publicados entre os anos de 2017 a 2020, descritos em português, que apresentassem estudos acerca do surto da doença coronavírus no âmbito mundial. Resultados: Em 2002 e 2003 a publicados entre os anos de 2017 a 2020, descritos em português, que apresentassem estudos acerca do surto da doença coronavírus no âmbito mundial. Resultados: Em 2002 e 2003 a MERS-CoV causador dos surtos que ocorreram no Oriente Médio, em que foi registrado 2.494 casos em 27 países e dessa vez com 858 mortes e uma taxa de letalidade de $34 \%$. Assim, em avaliaç̃̃es laboratoriais foram em uma faixa etária acima dos 50 anos e estes apresentaram febre $(>37,8)$, tosse, sintomas respiratórios, coriza, dores musculares, confusão mental, dor de cabeça, dor de garganta, mialgia/artralgia, gânglios linfáticos aumentados, desidratação, inapetência, diarreia, náuseas e vômitos, presença de manchas na pele. Conclusão: A chegada acelerada do novo vírus coloca em discussão a estrutura da vigilância sanitária e epidemiológica existente no país, principalmente numa época em que a houve cortes de investimentos no Sistema Único de Saúde (SUS) e nas pesquisas, fragilizando a capacidade de detecção precoce e de resposta até mesmo para o seu tratamento.

Palavras-chave: Coronavírus; Saúde Pública; Prevenção.

\section{Covid-19, the new coronavirus: an emergency alert for the main public health prevention strategies}

\begin{abstract}
Introduction: The new Coronavirus, a type of virus, already identified, as an etiological agent that triggers an alarming outbreak of a respiratory disease causing pneumonia of unknown origin which triggered the primary spread in the city of Wuhan, located in China. Objective: To know the possible forms of guidance for the National Health Surveillance System agencies in partnership with the Primary Health Care services, to act in the identification of cases, carrying out notifications and in the referencing of suspected cases due to infection due to the poronavirus. Method: For the development of this study, a literature review was carried out, characterized in the analysis of the information available at a given moment and about a specific Coronavirus. Method: For the development of this study, a literature review was carried out, characterized in the analysis of the information available at a given moment and about a specific
problem. Thus, the present study is descriptive in nature, with a qualitative approach. The search for articles took place in the Scientific Electronic Library Online (SciELO), Virtual Health Library (VHL) and Google Scholar databases. For the inclusion criteria used, articles published between the years 2017 to 2020, described in Portuguese, that presented studies on the outbreak of coronavirus disease worldwide were selected. Results: In 2002 and 2003 China had about 8,096 cases in several countries and with a total of 774 deaths, with a lethality rate of $9.5 \%$, while MERS-CoV. In 2012, this new episode was due to the MERS-CoV that caused the outbreaks that occurred in the Middle East, in which 2,494 cases were recorded in 27 countries and this time with 858 deaths and a fatality rate of $34 \%$. Thus, in laboratory evaluations they were in an age group above 50 years and they presented fever $(>37.8)$, cough, respiratory symptoms, runny nose, muscle pain, mental confusion, the skin. Conclusion: The accelerated arrival of the new virus calls into question the structure of health and epidemiological surveillance existing in the country, especially at a time when there were cuts in investments in the Unified Health System (SUS) and in research, weakening the capacity for early detection and response even to your treatment.
\end{abstract}

Keywords: Coronavirus; Public health; Prevention.

\section{Topic: Enfermagem em Saúde Pública}

Reviewed anonymously in the process of blind peer.

Agne Clecia Reis Silva (iD)

Centro Universitário AGES, Brasil

http://lattes.cnpq.br/0275634808118890

http://orcid.org/0000-0001-5427-032X

agnesilva123@gmail.com

Taylaine Santos de Jesus (iD)

Centro Universitário AGES, Brasil

http://lattes.cnpq.br/1840033938098983

http://orcid.org/0000-0002-6158-1721

taylaine.sts@outlook.com

Sergio de Santana Santos (ii)

Centro Universitário AGES, Brasil

http://lattes.cnpq.br/5584385034228449

http://orcid.org/0000-0003-1030-1854

enfersergiosantana@outlook.com
Received: $19 / 02 / 2020$

Approved: 04/05/2020
Gilderlaine de Jesus Santos (iD)

Centro Universitário AGES, Brasil

http://lattes.cnpq.br/0415340658123071

http://orcid.org/0000-0002-2492-5425

elainesantos2224862@gmail.com

Wellington Pereira Rodrigues (D)

Centro Universitário AGES, Brasil

http://lattes.cnpq.br/2798105983752891

http://orcid.org/0000-0002-0993-6871

wellington life@live.com
Referencing this:

SILVA, A. C. R.; JESUS, T. S.; SANTOS, S. S.; SANTOS, G. J.; RODRIGUES W. P.. Covid-19, o novo coronavírus: um alerta emergencial para as principais estratégias de prevenção da saúde pública. Scire Salutis, v.10, n.2, p.26-34, 2020. DOI: http://doi.org/10.6008/CBPC2236$\underline{9600.2020 .002 .0004}$ 


\section{INTRODUÇÃO}

O novo Coronavírus 2019 (2019-nCoV) um tipo de vírus, já identificado, como um agente etiológico desencadeador de um alarmante surto de uma doença respiratória ocasionando uma pneumonia de origem desconhecida, que desencadeou a disseminação primária na cidade de Wuhan, localizada na China. As autoridades relataram o ocorrido em 31 de dezembro de 2019, onde as vítimas da infecção nessa localidade se tratavam de comerciantes e pessoas que frequentavam a localidade do mercado, local onde comercializam frutos do mar, animais vivos e mortos. Dessa forma, surgiram evidências de que as pessoas que tinham o contato direto com esses animais, consequentemente já haviam entrado em contato com as vísceras e os fluídos corpóreos dos animais neste mercado (BRASIL, 2020).

Após as evidências, partiram para as investigações laboratoriais com a amostra de uma cultura de lavado bronquioalveolar dos indivíduos que apresentaram a pneumonia de origem desconhecida, em que os resultados trouxeram como diagnóstico um novo coronavírus, com denominação provisória de 2019-nCoV. Dessa forma, vale ressaltar que os coronavírus (CoVs) segundo Brasil (2020) podem ser classificados de acordo com a Taxonomia em ordem Nidovirales, na família Coronaviridae, e na subfamília Coronavirinae, respectivamente, a subfamília ainda engloba nessa distribuição 4 gêneros, sendo eles alfacoronavírus, betacoronavírus, gamacoronavírus e deltacoronavírus.

Após os resultados das investigações realizadas com esta amostra, foi possível a determinação de que as classes dos coronavírus podem ser encontradas em diversos tipos de hospedeiros, porém somente os morcegos são os principais reservatórios deste vírus que desencadeou o surto da infecção, iniciando com a pneumonia em Wuhan. No entanto, não se pode descartar a possibilidade de que outros animais como as aves, alguns animais mamíferos incluindo camelos, gatos selvagens asiáticos, ratos e cães também podem ser considerados possíveis hospedeiros do vírus, salientando que todos os vírus são parasitas intracelulares obrigatórios com o metabolismo ativo somente em contato com o hospedeiro (BRASIL, 2020).

Desse modo, conforme Brasil (2020) o coronavírus possui como agente etiológico um RNA viral da ordem Nidovirales, sendo os vírus do SARS-CoV e MERS-CoV, considerados de alta patogenicidade quando o vírus entra em contato e ocorre a instalação no hospedeiro, desencadeando os sinais e sintomas característicos das síndromes respiratórias e gastrointestinais nos indivíduos. Diante disso, após a identificação da virulência e do agente etiológico realizaram estudos onde efetuaram o sequenciamento genético deste RNA, uma fita única constituída por cerca de 30 mil bases nitrogenadas.

Desse modo, acabara contribuindo para o desenvolvimento de instrumentos que facilitaram o diagnóstico da biologia molecular que auxiliam nas descobertas de mais informações acerca deste novo coronavírus. Assim, por meio das análises do material genético, o Comitê Internacional de Taxonomia de Vírus (ICTV) passa a chamar de coronavírus 2 (SARS-COV-2). Logo, a doença causada pelo SARS-COV-2 recebeu nova denominação da Organização Mundial da Saúde (OMS) de COVID-19 (CHAVES et al., 2020).

Com relação ao modo de transmissão do coronavírus, estes por constituírem uma vasta família, são comuns em diferentes espécies de animais, com isso, no início do surto as primeiras pessoas que 
apresentaram as doenças respiratórias tinham algum contato com o mercado onde continham os animais, o que se sugeriu que a disseminação tinha ocorrido entre os animais e frutos do mar com as pessoas (CORRÊA FILHO, 2019).

Entretanto com as várias ocorrências de novos casos, de pessoas que não tiverem contato com o mercado e os animais do local, identificou-se que a disseminação da patologia também se dá de pessoapessoa, onde tiveram os primeiros casos também na China e em outros países como Japão, Alemanha e os Estados Unidos e agora o Brasil. Dando ênfase também para as transmissões ocorridas em unidades e âmbitos de saúde, como os casos de transmissão em hospitais da China e na França, servindo de alerta para a rede de serviços de saúde e da vigilância sanitária, epidemiológica e de imunizações promovendo a saúde e erradicando a incidência de novos casos (BRASIL, 2020).

Diante do pressuposto, acreditam-se que a transmissão, observando-se o período de incubação entre 5 e 12 dias, a transmissibilidade de pessoa-pessoa ocorreu devido o contato com respingos e gotículas advindas do trato respiratório no momento que a pessoa infectada tosse ou espirra. Outros casos já identificados, a forma de transmissão se deu por aerossóis em pacientes que foram submetidos a procedimentos direcionados ás vias aéreas, como aspiração e intubação. Além disso, muitos dos casos já denotados dessa transmissão, deixam de serem reconhecidos por apenas um surto e agora a disseminação passa a ter dimensão pandêmica entre as pessoas após o contato próximo, sendo que os profissionais da saúde que ofertam os cuidados e a assistência a essas pessoas tornam-se também vulneráveis a esse surto (SENHORAS, 2020).

Com isso, o período de transmissão dos indivíduos infectados pelo COVID-19 se dá por 7 dias após início da sintomatologia, no entanto, ainda não possuem estudos que definam informações acerca de quantos dias anteriores ao início dos sinais e sintomas, o indivíduo já infectado passa a promover a transmissão da virulência a população contribuindo assim, para a origem de grandes impactos na saúde pública, na economia do país e afins (SENHORAS, 2020).

Face ao exposto este estudo objetiva conhecer as possíveis formas de orientação para os órgãos Sistema Nacional de Vigilância em Saúde em parceria com os serviços da Atenção Primária à Saúde (APS), para atuarem na identificação de casos, realização de notificações e no referenciamento dos casos suspeitos pela infecção decorrente do Coronavírus, ofertando a resolubilidade da patologia e promovendo a saúde dos casos confirmados e ocasionados pela infecção sustentada; estabelecer uma estratégia funcional, de promoção de informações e ações orientando a população sobre a prevenção, objetivando evitar infecções virais; evitar a transmissibilidade do vírus nos profissionais da saúde no âmbito da saúde, e na comunidade; evitar que os casos clínicos já confirmados não evoluam para o óbito através do aporte clínico e multidisciplinar.

\section{METODOLOGIA}

Para o desenvolvimento deste estudo foi realizada uma revisão sistemática de literatura, caracterizando-se na análise das informações disponíveis em um dado momento e sobre uma problemática 
específica. Assim, o presente estudo é de natureza descritiva, com abordagem qualitativa conforme (LAKATOS et al., 2017).

A busca pelos artigos se deu nas bases de dados Scientific Electronic Library Online (SciELO), Biblioteca Virtual em Saúde (BVS) e Google Acadêmico. Para os critérios de inclusão utilizados, foram selecionados artigos publicados entre os anos de 2017 a 2020, descritos em português, que apresentassem estudos acerca do surto da doença coronavírus no âmbito mundial.

A pesquisa utilizou-se dos seguintes descritores: coronavírus, prevenção para coronavírus e profilaxias, nos quais foram excluídos os artigos que não se enquadravam nos critérios de inclusão e os que não se relacionavam com a doença coronavírus. Após a verificação dos critérios de inclusão e da exclusão de alguns artigos, este trabalho foi realizado com base em 14 artigos.

\section{RESULTADOS E DISCUSSÃO}

Tabela 1: Distribuição dos Distribuição dos artigos selecionados segundos os meios eletrônicos em 2020.

\begin{tabular}{|c|c|c|c|c|c|c|}
\hline Bases de dados & Título & Autores & $\begin{array}{c}\text { Ano de } \\
\text { publicação }\end{array}$ & $\begin{array}{l}\text { Método } \\
\text { aplicado }\end{array}$ & País & Resultados \\
\hline $\begin{array}{l}\text { Ministério da } \\
\text { Saúde }\end{array}$ & $\begin{array}{l}\text { Infecção Humana pelo Novo } \\
\text { Coronavírus (2019-nCoV). }\end{array}$ & BRASIL & 2020 & $\begin{array}{l}\text { Estudo } \\
\text { qualitativo, } \\
\text { quantitativo e } \\
\text { descritivo. }\end{array}$ & Brasil & $\begin{array}{l}\text { Devido ao grande surto do } \\
\text { COVID-19, os exames } \\
\text { laboratoriais dos casos novos } \\
\text { continuam em curso para } \\
\text { diagnóstico dos casos, enquanto } \\
\text { as demais populações devem } \\
\text { seguir os protocolos de } \\
\text { prevenção e isolamento. }\end{array}$ \\
\hline $\begin{array}{l}\text { Ministério da } \\
\text { Saúde }\end{array}$ & $\begin{array}{l}\text { Infecção Humana pelo Novo } \\
\text { Coronavírus (2019-nCoV). }\end{array}$ & BRASIL & 2020 & $\begin{array}{l}\text { Pesquisa } \\
\text { Bibliográfica }\end{array}$ & Brasil & $\begin{array}{l}\text { Evidenciou o alastramento do } \\
\text { surto do coronavírus, o que } \\
\text { ocasionou inúmeras vítimas, } \\
\text { declarando emergência em saúde } \\
\text { pública, necessitando de } \\
\text { diagnósticos e medidas de } \\
\text { prevenção dos agravos. }\end{array}$ \\
\hline $\begin{array}{l}\text { Ministério da } \\
\text { Saúde }\end{array}$ & $\begin{array}{l}\text { Protocolo de tratamento do } \\
\text { novo Coronavírus (2019- } \\
\text { nCov). }\end{array}$ & BRASIL & 2020 & $\begin{array}{l}\text { Revisão } \\
\text { Sistemática de } \\
\text { Literatura }\end{array}$ & Brasil & $\begin{array}{l}\text { Segundo contexto } \\
\text { epidemiológico do Brasil, é } \\
\text { essencial adotar o protocolo de } \\
\text { tratamento para influenza, sendo } \\
\text { distinto do COVID-19. }\end{array}$ \\
\hline $\begin{array}{l}\text { Ministério da } \\
\text { Saúde }\end{array}$ & $\begin{array}{l}\text { Plano de contingência para } \\
\text { epidemia da doença pelo } \\
\text { coronavírus } 2019 \text { (COVID-19) } \\
\text { do Distrito Federal. }\end{array}$ & BRASIL & 2020 & $\begin{array}{l}\text { Revisão } \\
\text { Sistemática de } \\
\text { Literatura }\end{array}$ & Brasil & $\begin{array}{l}\text { Diante deste cenário } \\
\text { epidemiológico, cabe } \\
\text { monitoração periódica, para } \\
\text { aplicação do protocolo padrão, } \\
\text { obtenção de resposta adequada } \\
\text { e adoção de medidas } \\
\text { correspondentes. }\end{array}$ \\
\hline $\begin{array}{l}\text { Ministério de } \\
\text { Saúde }\end{array}$ & $\begin{array}{l}\text { Plano de contingência da } \\
\text { Fiocruz diante da pandemia } \\
\text { da doença pelo SARS-CoV-2 } \\
\text { (Covid-19). }\end{array}$ & BRASIL & 2020 & $\begin{array}{l}\text { Revisão } \\
\text { Sistemática de } \\
\text { Literatura }\end{array}$ & Brasil & $\begin{array}{l}\text { É evidente que as necessidades } \\
\text { específicas existem e não devem } \\
\text { ser limitadas pelo contexto, onde } \\
\text { deve-se dar continuidade do } \\
\text { cuidado tanto ao coronavírus } \\
\text { como as demais doenças. }\end{array}$ \\
\hline Google Acadêmico & $\begin{array}{l}\text { SARS-COV-2, o novo } \\
\text { Coronavírus: uma reflexão } \\
\text { sobre a Saúde Única (One } \\
\text { Health) e a importância da } \\
\text { medicina de viagem na } \\
\text { emergência de novos } \\
\text { patógenos. }\end{array}$ & $\begin{array}{l}\text { CHAVES et } \\
\text { al. }\end{array}$ & 2020 & $\begin{array}{l}\text { Pesquisa } \\
\text { Bibliográfica }\end{array}$ & Brasil & $\begin{array}{l}\text { Esta epidemia deve ser } \\
\text { compreendida como um impacto } \\
\text { que engloba a natureza, o } \\
\text { homem; analisando as relações } \\
\text { existentes entre saúde } \\
\text { ambiental, animal e humana } \\
\text { ocasionando nas doenças atuais. }\end{array}$ \\
\hline $\begin{array}{l}\text { Scielo- Revista } \\
\text { Saúde em Debate }\end{array}$ & $\begin{array}{l}\text { A utopia do debate } \\
\text { democrático na vigilância em } \\
\text { saúde. }\end{array}$ & $\begin{array}{l}\text { CORRÊA } \\
\text { FILHO }\end{array}$ & 2019 & $\begin{array}{l}\text { Pesquisa } \\
\text { Bibliográfica }\end{array}$ & Brasil & $\begin{array}{l}\text { A vigilância em saúde deve } \\
\text { avançar em meio as doenças } \\
\text { emergentes, para garantir a } \\
\text { ampla notificação a todos, } \\
\text { garantindo as normas de } \\
\text { confidencialidade, para que a } \\
\text { tomada de decisão seja conjunta }\end{array}$ \\
\hline
\end{tabular}




\begin{tabular}{|c|c|c|c|c|c|c|}
\hline & & & & & & com todos. \\
\hline Google Acadêmico & $\begin{array}{l}\text { Fundamentos de } \\
\text { metodologia científica. }\end{array}$ & $\begin{array}{l}\text { LAKATOS } \\
\text { et al. }\end{array}$ & 2017 & Descritivo & Brasil & $\begin{array}{l}\text { Supri as necessidades existentes } \\
\text { na construção de trabalhos } \\
\text { científicos. Um trabalho que } \\
\text { possa sintetizar aspectos } \\
\text { didáticos para uso profissional } \\
\text { metódica, lógica e didática. }\end{array}$ \\
\hline $\begin{array}{l}\text { BVS - Caderno de } \\
\text { Saúde Pública }\end{array}$ & $\begin{array}{l}\text { Emergência do novo } \\
\text { coronavírus (SARS-Cov-2) e o } \\
\text { papel de uma vigilância } \\
\text { nacional em saúde oportuna } \\
\text { e efetiva. }\end{array}$ & LANA et al. & 2020 & $\begin{array}{l}\text { Pesquisa } \\
\text { Bibliográfica }\end{array}$ & Brasil & $\begin{array}{l}\text { O contexto de novas doenças } \\
\text { exige uma nova reestruturação } \\
\text { no sistema de notificação, sendo } \\
\text { necessário ampliar o SINAN, } \\
\text { sendo ideal a participação do } \\
\text { Ministério da Saúde, para fazer } \\
\text { relatórios temporal sem atrasos, } \\
\text { visando ações oportunas e um } \\
\text { sistema padrão ouro nacional. }\end{array}$ \\
\hline $\begin{array}{l}\text { Google Acadêmico } \\
\text { - Sociedade } \\
\text { Brasileira de } \\
\text { Pediatria }\end{array}$ & $\begin{array}{l}\text { Novo coronavírus (COVID- } \\
\text { 19) }\end{array}$ & SÁFADI & 2020 & $\begin{array}{l}\text { Pesquisa } \\
\text { Bibliográfica. }\end{array}$ & Brasil & $\begin{array}{l}\text { É notório que precisamos } \\
\text { conhecer mais e obter } \\
\text { informações sobre esse vírus, } \\
\text { transmissão, virulência e formas } \\
\text { de tratamento. Ofertando uma } \\
\text { visão crítica e reflexiva para a } \\
\text { doença. }\end{array}$ \\
\hline $\begin{array}{l}\text { Google Acadêmico } \\
\text { - Revista } \\
\text { Interdisciplinar em } \\
\text { Ciências da Saúde } \\
\text { e Biológicas. }\end{array}$ & $\begin{array}{l}\text { Resfriado comum: estudo } \\
\text { utilizando como instrumento } \\
\text { a interdisciplinaridade. }\end{array}$ & $\begin{array}{l}\text { SCHONS et } \\
\text { al. }\end{array}$ & 2019 & $\begin{array}{l}\text { Revisão de } \\
\text { Literatura }\end{array}$ & Brasil & $\begin{array}{l}\text { Existem vários tipos de vírus que } \\
\text { são agentes etiológicos para o } \\
\text { resfriado. É necessário a análise } \\
\text { de forma interdisciplinar sobre o } \\
\text { uso de medicamentos; sendo um } \\
\text { tipo de tratamento sistemático. }\end{array}$ \\
\hline $\begin{array}{l}\text { Google Acadêmico } \\
\text { - Boletim de } \\
\text { Conjuntura } \\
\text { (BOCA) }\end{array}$ & $\begin{array}{l}\text { Coronavírus e o papel das } \\
\text { pandemias na história } \\
\text { humana. }\end{array}$ & SENHORAS & 2020 & $\begin{array}{l}\text { Pesquisa } \\
\text { Bibliográfica }\end{array}$ & Brasil & $\begin{array}{l}\text { Embora a letalidade seja alta, a } \\
\text { difusão do vírus é elevada, } \\
\text { havendo grande disseminação da } \\
\text { doença, o que reflete na } \\
\text { economia dos países, } \\
\text { desencadeando um saldo } \\
\text { negativo no final. }\end{array}$ \\
\hline $\begin{array}{l}\text { Google Acadêmico } \\
\text { - Boletim de } \\
\text { Conjuntura } \\
\text { (BOCA) }\end{array}$ & $\begin{array}{l}\text { Novo Coronavírus e seus } \\
\text { impactos econômicos no } \\
\text { mundo. }\end{array}$ & SENHORAS & 2020 & $\begin{array}{l}\text { Pesquisa } \\
\text { Bibliográfica }\end{array}$ & Brasil & $\begin{array}{l}\text { Face ao contexto epidemiológico } \\
\text { decorrente da pandemia, gera } \\
\text { interferências ao mercado } \\
\text { financeiro também, trazendo } \\
\text { preocupação com os impactos } \\
\text { humanos e econômicos, sendo } \\
\text { essencial a criação de políticas } \\
\text { econômicas, sociais, saúde e } \\
\text { afins. }\end{array}$ \\
\hline $\begin{array}{l}\text { Google Acadêmico } \\
\text { - Revista Direito e } \\
\text { Práxis. }\end{array}$ & $\begin{array}{l}\text { A emergência do novo } \\
\text { coronavírus e a "lei de } \\
\text { quarentena" no Brasil. }\end{array}$ & $\begin{array}{l}\text { VENTURA } \\
\text { et al. }\end{array}$ & 2020 & $\begin{array}{l}\text { Pesquisa } \\
\text { Bibliográfica }\end{array}$ & Brasil & $\begin{array}{l}\text { As medidas de saúde já existiam, } \\
\text { porém, a lei é um avanço, assim, } \\
\text { a lei necessita de } \\
\text { aperfeiçoamento para validar sua } \\
\text { eficácia, tendo o SUS como eixo } \\
\text { de solução dos problemas } \\
\text { emergentes em saúde. }\end{array}$ \\
\hline
\end{tabular}

Após o decorrer da disseminação do surto e os relatos das autoridades sanitárias da China sobre os milhares de casos já confirmados e das centenas de mortes decorrentes do coronavírus (COVID-19), bem como a detecção e diagnósticos por meio dos testes realizados em diversos países, acometendo assim, principalmente os adultos em uma faixa etária que compreende acima dos 60 anos de idade e portadores de comorbidades. Diante desse episódio, a OMS declarou em 30 de janeiro de 2020 a ocorrência de um surto e mais especificamente se tratando de uma Emergência de Saúde Pública e de Importância Internacional (ESPIN) através da Portaria MS n 188, e conforme Decreto $n^{\circ}$ 7.616, de 17 de novembro de 2011 (BRASIL, 2020).

Em 2002 e 2003 a China teve cerca de 8.096 casos em vários países e com um total de 774 mortes, com uma taxa de letalidade de 9,5\%, enquanto MERS-CoV. Já em 2012 esse novo episódio foi decorrente do MERS-CoV causador dos surtos que ocorreram no Oriente Médio, em que foi registrado 2.494 casos em 27 
países e dessa vez com 858 mortes e uma taxa de letalidade de 34\% (SÁFADI, 2020).

Desse modo, é importante salientar que os dados ratificam que até o ano de 2019, eram conhecidas cerca de 6 espécies do coronavírus, dentre as quais quatro delas são os alphas 229E, NL63 e betas OC43 e HKU1 consideradas espécies de alta prevalência, onde pacientes com a sintomatologia apresentam resfriados e infecções leves. Já as duas outras cepas Severe Acute Respiratory Syndrome Coronavirus (SARSCoV) e a Middle East Respiratory Syndrome Coronavirus (MERS-CoV) associadas aos quadros respiratórios graves e fatais (SÁFADI, 2020).

Assim, a alta prevalência do coronavírus, tendo a sua ampla distribuição pelo mundo associado à sua diversidade e variabilidade genética e as oportunidades de recombinação; possuindo uma forte interação com humanos e animais, facilitando assim, o surgimento de novas cepas do coronavírus, consequentemente a sua taxa de prevalência e incidência também tende a se elevar, provocando o aumento dos números de casos e a letalidade ocasionada pela doença (SÁFADI, 2020).

Tendo em vista a história clínica da doença que ocorre desde o período médio de incubação para a infecção pelo coronavírus que se dá entre 5 e 12 dias, é importante ter conhecimento que o período de transmissibilidade dos pacientes que estão infectados pelo vírus que ocorre em média de 7 dias, que se dá ou não com o aparecimento das primeiras sintomatologias. Dessa forma, o espectro clínico da infecção é amplo e pode variar desde um resfriado, a uma pneumonia e levar o óbito do infectado (BRASIL, 2020).

Assim, em avaliações laboratoriais foram em uma faixa etária acima dos 50 anos e estes apresentaram febre $(>37,8)$, tosse, sintomas respiratórios, coriza, dores musculares, confusão mental, dor de cabeça, dor de garganta, mialgia/artralgia, gânglios linfáticos aumentados, desidratação, inapetência, diarreia, náuseas e vômitos, presença de manchas na pele. Dentre as complicações provenientes dessa infecção com o agravamento do quadro clínico destacamos a Síndrome Respiratória Aguda Grave (SRGA), lesão cardíaca aguda, infecção secundária, pneumonia e pneumotórax (BRASIL, 2020).

O diagnóstico exerce um papel fundamental na análise da patogenicidade da infecção no hospedeiro, e pode ser feito em 3 fases, sendo eles o diagnóstico clínico que vai depender da abordagem epidemiológica e do exame físico céfalo-podal, sendo questionado nesse momento sobre o histórico de viagem para o exterior e a aproximação com pessoas que viajaram. Essas e outras informações devem ser anotadas no prontuário clínico e estudadas, para que iniciem as investigações epidemiológicas e sanitárias (CORREA FILHO, 2019).

Além desse, podem ser realizados o diagnóstico laboratorial através da técnica Reverse Transcription Polymerase Chain Reaction (RT-PCR) em tempo real que é padrão ouro, realizado nos Centros Nacionais de Influenza (NIC) que são referências como os Laboratórios Centrais de Saúde Pública (LACEN), realizando a coleta de secreção de trato respiratório superior e inferior e com a contribuição do sequenciamento do genoma. Ainda assim, o diagnóstico diferencial, quando as características clínicas não são específicas e podem ser semelhantes a outros vírus respiratórios como a influenza, para influenza, rinovírus, adenovírus e outros coronavírus (SÁFADI, 2020).

O surgimento de complicações determina a hospitalização imediata. Em se tratando de ações a serem 
realizadas com os indivíduos infectados deve-se seguir um protocolo de atendimento e tratamento para que a assistência seja eficaz e o quadro clínico seja reestabelecido. Em se tratando de tratamento para o coronavírus, não existe um tratamento específico ou uma vacina para a doença, contudo, estão sendo usados medicamentos experimentais e combinações medicamentosas (SÁFADI, 2020).

Assim, remdesivir, lopinavir (LPV), ritonavir (RTV) ou lopinavir-ritonavir e interferon Beta1b podem ser considerados em casos extremos de pacientes graves. E em casos de Síndrome Respiratória Aguda ou Choque associado ao coronavírus podem ser utilizados Lopinavir-ritonavir $400 \mathrm{mg} / 100 \mathrm{mg}$ via oral, 2 vezes ao dia, durante 10 a 14 dias, podendo-se associar ou não Peg-Interferon-alfa2a 180 mcg via subcutânea em dose única. Além disso, as campanhas de vacinação contra a gripe já foram disponibilizadas, com o intuito de erradicar a origem de novas infecções por outros vírus (VENTURA et al., 2020).

Como ações a serem desempenhadas se tornam essencial que as gestões em saúde promovam as ações integradas entre vigilância em saúde, LACEN e outros órgãos envolvidos na prevenção e controle; além disso, sejam eficientes em relação a sensibilização da rede de serviços assistenciais públicos e privados sobre o cenário epidemiológico da infecção, garantindo e monitorando sempre o estoque de insumos necessários para diagnóstico. Por fim, garantir o estoque estratégico de medicamento para o atendimento de casos já confirmados, por meio dos testes (SCHONS et al., 2019).

As equipes de saúde em parceria com essas gestões devem estar atentas para a deteç̧ão dos casos e realizem as notificações corretamente, visto que, acabam possibilitando a deflagração de forma imediata das medidas de controle interrompendo e erradicando a circulação do vírus e a sua consequente transmissão (SCHONS et al., 2019).

No atendimento, levam-se em consideração os tipos de diagnósticos que são importantes para o manejo da infecção. Neste momento, deve-se analisar a presença da sintomatologia e após a confirmação da infecção o médico deve analisar a necessidade de hospitalização e se não for necessária essa conduta e este opte pelo isolamento social, o profissional da saúde poderá solicitar RX de tórax, hemograma e testes bioquímicas, que irão determinar a condição clínica do paciente. Os pacientes positivos para o COVID-19 recebem orientações acerca do controle da infecção, a prevenção da transmissão por contato com outras pessoas, e estar atento aos possíveis sinais de complicações (VENTURA et al., 2020).

Em relação a vigilância sanitária, dentro de suas atribuições em episódios que desencadeiam (surtos, endemias, epidemias e pandemias) deve promover as orientações sobre a utilização dos equipamentos de proteção individual e coletivo, necessários aos atendimentos de casos e demais medidas de precaução. Verificando junto à rede de atenção a adequação e cumprimento de medidas que normatizam a biossegurança, sendo estas indicadas para o atendimento de casos suspeitos e até mesmo os casos já confirmados. Sendo que se deve realizar a notificação imediata dos casos em 24 horas, no Centro de Informações Estratégicas em Vigilância em Saúde (CIEVS) (LANA et al., 2020).

Além disso, um dos principais objetivos dessa parceria é a informação das medidas necessárias a serem adotadas pelos profissionais de diversas áreas, como também para a população. Elaborando em parceira com as áreas técnicas para a confecção de materiais informativos e/ou para educação em saúde 
sobre o COVID-19 e distribuí-los aos profissionais de saúde, para que estes possam conduzir a atuação e a propagação da informação (LANA et al., 2020).

A implementação da adesão de precauções padrão constitui uma das principais medidas de prevenção comunitária e mundial para a transmissão entre os indivíduos infectados e os profissionais de saúde, envolvidos na assistência ofertada a esses pacientes como suporte estratégico adotado no cuidado de todos os pacientes durante toda a assistência, independentemente dos fatores de risco ou doença base, garantindo que as políticas e práticas internas funcionem nesse contexto pandêmico.

Como medida de prevenção se deve levar em consideração que a transmissão entre as pessoas ocorre por meio de gotículas e do contato. Enquanto isso, a transmissão por aerossóis limita-se a procedimentos que geram aerossóis, como intubação orotraqueal, aspiração aberta das vias aéreas, fisioterapia respiratória, ressuscitação cardiopulmonar e coleta de amostra para diagnostico etiológico (VENTURA et al., 2020).

A minimização da exposição, implica em estratégias para o combate dessa infecção onde deve-se inicialmente evitar o contato próximo com pessoas com infecções respiratórias agudas, e demais, independente de terem viajado ou não para outras localidades, deve-se priorizar pelo isolamento social; ficar com um distanciamento de 1,5 a 2 metros de distância das pessoas, com esse intuito foi criada a Lei de quarentena; priorizar por critérios de triagem; lavar frequentemente as mãos, com água e sabão, seguindo os passos corretos para a lavagem e em seguida realizar a fricção com álcool em gel a 70\%; cobrir nariz e boca ao espirrar ou tossir e realizar a higienização das mãos após esse episódio; evitar tocar nas mucosas dos olhos; não compartilhar objetos de uso pessoal, como talheres, pratos, copos ou garrafas; manter os ambientes bem ventilados e realizar a limpeza de superfícies, equipamentos e do ambiente; provisão de insumos e recursos humanos para controle e prevenção da infecção (VENTURA et al., 2020).

\section{CONCLUSÕES}

A chegada acelerada do novo vírus coloca em discussão a estrutura da vigilância sanitária e epidemiológica existente no país, principalmente numa época em que a houve cortes de investimentos no Sistema Único de Saúde (SUS) e nas pesquisas, fragilizando a capacidade de deteç̧ão precoce e de resposta até mesmo para o seu tratamento. Tendo como protagonista o Brasil, que precisa acompanhar o avanço de conhecimentos científicos gerados no exterior e preparar-se para as pesquisas e demandas específicas que surgirão, incluindo diagnóstico, assistência, prevenção e promoção da saúde específica à doença. Portanto, quando o alerta para o novo coronavírus foi disparado, houve fragilidades na área da saúde e na educação, respectivamente concluindo-se que o SUS não está preparado para essa pandemia.

Face ao exposto acerca da emergência que exige uma reestruturação na forma como doenças são notificadas no país em especial a nova pandemia causada pelo coronavírus. É preciso investir em um novo SINAN, baseado em tecnologias especializadas tanto para facilitar a notificação como para permitir a disseminação e análise de dados de forma eficiente, seguindo os princípios e diretrizes da epidemiologia. É fundamental que o Ministério da Saúde desenvolva instrumentos integrados com os dados acerca dos 
aspectos importantes em relação a transmissão diagnostico, tratamento, promoção e prevenção das doenças nesta era de alta transmissibilidade comunitária global.

É possível considerar a adesão de um sistema flexível o suficiente para permitir a diminuição de novos agravos, desenvolvendo medidas de prevenção e tratamento específicos para a doença, ainda inexistentes. Quanto à comunicação desse tipo de informação acerca dos dados, disponibilização destes; tendo em vista, o acesso ao sistema de notificação é essencial, uma vez que viabiliza a construção de relatórios para o acompanhamento real e espacial dos casos suspeitos, notificados e confirmados em tempo hábil. Sendo essencial o financiamento e elaboração de pesquisas que viabilizem a construção de informações e dados para o suporte preventivo da doença, desenvolvimento de um tratamento específico, e futuramente a fabricação de uma vacina que corresponda aos seis tipos desses vírus; contribuindo para a saúde mundial da população. Logo, quaisquer tipos de dados apresentados nesta pesquisa podem ser passados por atualizações de acordo com a prevalência do COVID-19, com base no Ministério da Saúde (MS) e da Organização Mundial da Saúde (OMS).

\section{REFERÊNCIAS}

BRASIL. Secretaria de Estado de Saúde. Plano de contingência para epidemia da doença pelo coronavírus 2019 (COVID-19) do Distrito Federal. Brasília: Secretaria de Estado de Saúde, 2020.

BRASIL. Ministério da Saúde. Plano de contingência da Fiocruz diante da pandemia da doença pelo SARS-CoV-2 (Covid-19). Brasília: Fundação Osvaldo Cruz, 2020.

BRASIL. Ministério da Saúde. Protocolo de tratamento do novo Coronavírus (2019-nCoV). Brasília: Ministério da Saúde, 2020.

BRASIL. Ministério da Saúde. Infecção Humana pelo Novo Coronavírus (2019-nCoV). Centro de Operações de Emergências em Saúde Pública - COE-nCoV. Brasília: Ministério da Saúde, 2020.

CHAVES, T. S. S.; BELLEI, N.. SARS-COV-2, o novo Coronavírus: uma reflexão sobre a Saúde Única (One Health) e a importância da medicina de viagem na emergência de novos patógenos. Revista Medicina, São Paulo, v.99, n.1, p.1-4, 2020.

CORRÊA FILHO, H. R.. A utopia do debate democrático na vigilância em Saúde. Revista Saúde em Debate, Rio de Janeiro, v.43, n.123, p.979-986, 2019.
LAKATOS, E. M.; MARCONI, M. A.. Fundamentos de metodologia científica. 7 ed. São Paulo: Atlas, 2017.

LANA, R. M.; COELHO, F. C.; GOMES, M. F. C.. Emergência do novo coronavírus (SARS-CoV-2) e o papel de uma vigilância nacional em saúde oportuna e efetiva. Caderno de Saúde Pública, v.36, n.3, 2020.

SÁFADI, M. A. P.. Novo coronavírus (COVID-19). Sociedade Brasileira de Pediatria, 2020.

SCHONS, A. M.; TOBIN, K. F.; ANDRADE, V. R. M.. Resfriado comum: estudo utilizando como instrumento a interdisciplinaridade. Revista Interdisciplinar em Ciências da Saúde e Biológicas, v.3, n.1, p.55-66, 2019.

SENHORAS, E. M.. Novo Coronavírus e seus impactos econômicos no mundo. BOCA: Boletim de conjuntura, Boa Vista, v.1, n.2, 2020

VENTURA, D. F. L.; AITH, F. M. A.; RACHED, D. H.. A emergência do novo coronavírus e a 'lei de quarentena' no Brasil. Revista Direito e Práxis, Rio de Janeiro, p.1-38, 2020.

A CBPC - Companhia Brasileira de Produção Científica (CNPJ: 11.221.422/0001-03) detém os direitos materiais desta publicação. Os direitos referem-se à publicação do trabalho em qualquer parte do mundo, incluindo os direitos às renovações, expansões e disseminaç̃̃es da contribuição, bem como outros direitos subsidiários. Todos os trabalhos publicados eletronicamente poderão posteriormente ser publicados em coletâneas impressas sob coordenação da Sustenere Publishing, da Companhia Brasileira de Produção Científica e seus parceiros autorizados. Os (as) autores (as) preservam os direitos autorais, mas não têm permissão para a publicação da contribuição em outro meio, impresso ou digital, em português ou em tradução. 